\title{
Controversies and New Hypotheses on Exercise-Induced Bronchospasm in Hot and Humid Air
}

\author{
MESSAN Folly
}

\begin{abstract}
Bronchospasm is a chronic disease that affects the respiratory airways in both general and sporting populations. Bronchospasm has been mainly studied and documented extensively in athletes in continental climates of cold and dry air. The prevalence values observed for this disease were increased in these athletes. On the other hand, the prevalence declined among athletes acclimated to the hot and humid air climate. As a result, the quality of inhaled ambient air appears to be a determining factor in the pathophysiology of bronchospasm. Thus, in recent years, there has been controversy concerning the role of warm moist air in exacerbating or alleviating bronchospasm. Previous studies have suggested that the high temperature of inhaled air during physical exertion is an explanation for the low prevalence values. However, studies performed in tropical areas highlight the high prevalence values of bronchospasm. This review is based on explanatory hypotheses related to changes in airflow and the effects of heat exchange and freshness on the epithelium. Finally, the induced effects are addressed under conditions where the temperature of the inhaled ambient air is lower or higher than that of the body fixed at $37^{\circ} \mathrm{C}$. On the basis of the assumptions made in this review, we suggest that exercise-induced bronchospasm in athletes is just as important in hot and humid air conditions as it is in cold and dry air conditions. The variability in the prevalence values of bronchospasm on which the controversies are based is mainly due to different states of training of the subjects, the nature and intensity of the effort, the various parameters and diagnostic criteria of the sportsmen, and assessments of bronchospasm and different modes of breathing. We hypothesized that in cold and dry air environments, the small lower airways of athletes are more vulnerable than those of their counterparts to pathophysiology in hot and humid climates. Professional sportsmen who specialize in long-distance endurance sports therefore truly expose their small airways to various pathologies.
\end{abstract}

Index Terms- Exercise-induced bronchospasm; Controversy; Hypothesis; Hot and humid air.

\section{INTRODUCTION}

Chronic respiratory disease is one of the world's leading global health system issues [1], [2]. Indeed, asthma, a chronic disease of the respiratory airways, affects more than 300 million people worldwide [3], [4] with a significantly increased incidence in recent decades [5]-[7]. Exercise-induced asthma and bronchospasm (EIB) are two terms that describe the same pathophysiological

MESSAN Folly, Unit of Respiratory, Hormonal and Gerontological Explorations of the Sportsman, INJEPS; University of Abomey-Calavi, (Benin) phenomenon. Bronchospasm is influenced by several variables, including environmental and climatic conditions. Indeed, EIB has been mainly studied and documented sufficiently in continental climates of cold and dry air [8]-[10]. Athletes who train and practice in cold air and/or a dry atmosphere would be more sensitive to bronchospasm and have a higher prevalence. Accordingly, Wilber et al. [10] examined a group of 14 American skiers at the 1998 Olympic Games and observed a prevalence of $57 \%$ among women, $43 \%$ among men and $50 \%$ for the entire team, under temperatures varying from $-18{ }^{\circ} \mathrm{C}$ at $0{ }^{\circ} \mathrm{C}$ and a relative humidity of $30-50 \%$. In a team of 26 Olympic level ice hockey players, a prevalence of $15 \%$ was observed only among women at ambient temperatures ranging from 10 to 13 ${ }^{\circ} \mathrm{C}$ and a relative humidity of $40-45 \%$. In a group of 60 ice sprinters, a prevalence of $50 \%$ among women and $33 \%$ among men was observed at temperatures ranging from 8 to $10{ }^{\circ} \mathrm{C}$ and a relative humidity of $30-35 \%$. From this work, the highest prevalence $(50 \%)$ was recorded under the coldest temperatures, and the lowest $(15 \%)$ was obtained under the highest temperatures. On the other hand, EIB prevalence values would be lower for athletes acclimated to hot and humid air conditions. As expected, the quality of the inhaled ambient air may be a determining factor that can exacerbate or attenuate bronchospasm. Chen and Horton [11] and McFadden et al. [12], [13] simulated an atmosphere of hot, humid air in the laboratory by raising the ambient air temperature to $36^{\circ} \mathrm{C}$ and the relative humidity to $100 \%$. At the end of this experiment, the mean values of ventilatory parameters observed before exercise compared to those recorded after exercise showed differences that were not significant. Consistently, a recent work by Gomes et al. [14] showed a low prevalence of EIB of $7 \%$ among 54 Brazilian semi-professional football players who train generally in a hot climate ranging from $23{ }^{\circ} \mathrm{C}$ to $32{ }^{\circ} \mathrm{C}$ and an average relative humidity between $70 \%$ and $85 \%$. From these results, the authors concluded that the hyperventilation of hot, humid air, to which athletes are subjected, can mitigate the process of bronchospasm. However, Messan et al. [15] found a prevalence of $26 \%$ among asymptomatic basketball players in hot air and humid conditions in Benin. Nsompi et al. [16] observed $33 \%$ in Congolese runners in hot and humid condition. In another study carried out in Abidjan in the Ivory Coast, Ouattara et al. [17] reported an asthma prevalence of $42.6 \%$ obtained after a stress test, with a Forced Expiratory Volume in one second (FEV) of at least $10 \%$ for sportsmen in hot $\left(30.1^{\circ} \mathrm{C}\right)$ and wet $(82.6 \%)$ climates. Agodokpessi et al. [18] found an asthma prevalence of $40 \%$ among African athletes in the hot and humid climate of Benin. Therefore, in 
light of these contradictory results, the present review proposes to rely not only on the pathophysiology of bronchospasm but also on new scientific knowledge to shed light on the controversies related to bronchospasm induced by exercise in hot and humid air environments. To this end, a research strategy was conducted in December 2018 with the main electronic databases of MEDLINE, EMBASE and CENTRAL to search for publications related to exercise-induced bronchospasm using the keywords "bronchospasm", "asthma, "hot and humid climate", "cold and dry climate", "prevalence".

\section{STATE OF KNOWLEDGE}

\section{Introductory Summary}

The pathophysiology of exercise-induced bronchospasm in athletes is not yet well known. However, two streams of thought each propose explanatory theories, namely, the theory of dehydration / osmolarity and the theory of cooling / warming [12], [13], [19]. These theories are based on bronchoconstriction caused by the inhalation of a hyperosmolar saline solution at rest. By analogy, the authors propose these hypotheses according the type of hyper osmolarity of the airways induced by hyperventilation at the origin of the bronchospasm observed in sportsmen. In fact, the gradual increase in the intensity of the exercise induces an increase in the ventilatory frequency. Similarly, for the inspired air to reach the lower airways, it must be warmed and saturated with water vapour. To this end, the cells of the upper airways intervene by yielding water in the form of heat to condition the inspired air. As a result of this dehydration, an increase in $\left[\mathrm{Na}^{+}\right],\left[\mathrm{Cl}^{-}\right],\left[\mathrm{Ca}^{2+}\right],\left[\mathrm{K}^{+}\right]$ions is observed, which would cause the hyperosmolar state of the airways and induce bronchial spasm.

The conditioning (saturation and warming) of the inspired air during physical exercise begins at the oro-naso-pharynx complex and reaches the trachea bronchial tree. Inspired ambient air, from the mouth to the periphery of the lungs, is exposed to the effects of warming and saturation from the airway epithelium. The net effect of this heat exchange during inspiration would be the "cooling of the airways" [15], [16], [20], [21]. This theory suggests a transfer of heat from the blood vessels of the small bronchi to the pulmonary blood vessels. Indeed, at the end of the exercise, this heat transfer is followed by dilation, warming and an increase in the blood flow of the pulmonary vessels. This hypothesis is based on the vascularization of the sub-epithelial capillaries, which ensures the connection between the trachea and the small bronchi. As a result, engorgement of these vessels could exert physical pressure on the airways, resulting in bronchospasm. The fundamental postulate of the warming hypothesis is based on an increase in the internal temperature of the airways, mimicking the increase in blood flow in the airways [15], [20]. However, the authors noted that the warming effect could simply be due to the prolonged retention of the air in alveoli. On the other hand, the amount of blood circulating in the bronchi cannot justify the increased heat in the airways since this amount of blood represents only approximately $1 \%$ of the cardiac output [17], [22].

Altogether, the hyperventilation of cold, dry, or hot and humid air, on the one hand, and the cooling and warming mechanisms of the airways, on the other hand, may represent various explanations for the high prevalence rates of asthma observed in the sporting population.

\section{SYNTHESIS OF THE CONTROVERSIES}

The work of Chen and Horton [11] and McFadden et al. [12] was conducted under conditions similar to those of warm and humid air zones, and the results were inconclusive in the sense of confirmed bronchospasm. These findings were accepted because exercise-induced bronchospasm was primarily studied in cold, dry air with high prevalence values. It is important to note that the hot and humid air conditions were simulated with subjects acclimatized to cold, dry air. A recent work by [14] seems consistent with this strategy, as these authors highlighted a low prevalence of EIB of $7 \%$ among 54 Brazilian semi-professional football players in hot and humid climates. In contrast, previous studies by Messan et al. [15], Ouattara et al. [17] and Agodokpessi et al. [18] found prevalence values of $42 \%$ and $42 \%$ in Ivorian and African basketball players, respectively, under hot and humid air conditions. However, the physiological adaptation of subjects to cold and dry air conditions, on the one hand, and hot and humid air conditions, on the other hand, can exacerbate or attenuate the occurrence of EIB. In addition, the disparity in EIB prevalence values observed under different air conditions is at the root of these controversies. Indeed, researchers are not unanimous on a certain number of concerns related to EIB diagnosis; however, studies have shown that the deterioration of respiratory parameters in athletes is due to pollution [23]. Thus, the practice of sports activities during the summer when the ozone level $\left(\mathrm{O}_{3}\right)$ is the highest would also favour the development of the bronchial inflammatory process [24]. Moreover, according to the Hinds model, for a quantity of $100 \%$ nanoscale particles, $80 \%$ are retained in the nose and pharynx, while the remaining $20 \%$ penetrate the trachea and bronchi [25]. The turbulence induced at each bronchial division increases with increasing respiratory rate and maintains these particles in the bronchial tree. Studies by Bruske-Hohlfeld et al. [26] have shown that the increase in the level of air pollution from fine particulate matter was particularly due to vehicle emissions. Similarly, EIB assessment results differ depending on whether they were derived from field and/or laboratory tests. In fact, to induce the variability of respiratory function by exercise, the suggested intensity is at least $85 \%$ of the maximum heart rate [27]. Other studies, however, suggest intensities ranging from 95 to $100 \%$ of maximal effort in athletes [9]. While the level of exercise intensity is generally not a problem in EIB assessments for amateur athletes, it is not always easy to manage in high-performance athletes. Indeed, the physical capacity can be underestimated during laboratory tests because the maximum tolerated intensity is often not consistent with the actual physical capacity of the sportsman. Evaluations in the laboratory do not take into account the realities of the actual environment of the sportsmen, such as the atmosphere of competitive rivalries, encouragements from the public, variations in itineraries and the ambient conditions. However, the measurements made under the actual conditions of the athletes are not always reliable because of disturbances related to the mobility of the subject. On the other hand, in the laboratory, the measurements can be 
precise but are not reliable because the subjects do not manage to express their actual physical potentiality.

A questionnaire, as another means of investigation of EIB, aims to assess wheezing dyspnoea, its conditions of appearance, seasonal variability or permanence. The questionnaire aims to reveal, among the antecedents or clinical signs, the existence of asthma associated or not with the effort. However, questionnaires based on the clinical manifestations of symptoms as the sole means of investigation are not reliable for evaluating EIB. Indeed, Thole [28], Rundell [29] and Bougault [30] showed that in athletes, the absence of a clinical symptomatology is not necessarily synonymous with the non-existence of bronchial hyperreactivity. Indeed, different authors have shown that symptoms do not always coexist with EIB [31], [32]. Another source of controversy is that the evaluation criteria for EIB and the nature of the sports activities of the subjects differ widely according to the studies. Indeed, while some authors adopt the variations in FEV, peak expiratory flow and expiratory flow from $25 \%-75 \%$ of the vital capacity as criteria, others have used FEV as the evaluation criterion for EIB [33], [28]. Similarly, the decrease in the percentage of the parameter retained after stress testing is not unanimous. As a result, there were divergences with regard to EIB parameters and diagnostic criteria. While some studies propose a decrease in FEV of at least $10 \%$ to justify the existence of EIB, others propose a $7 \%$ decrease. Altogether, these reasons may explain the variations in EIB prevalence values.

\section{PLAUSIBLE ASSUMPTIONS}

\section{1) General Influences on the Inspired Air}

The inspired air needs to be conditioned to evolve from the oro-naso-pharynx complex to the tracheobronchial tree of the lower airways. The conditioning of the inspired air involves saturation in water and warming to body temperature, which is $37{ }^{\circ} \mathrm{C}$. To this end, inhaled air is exposed to the effects of warming and saturation from the airway epithelium. The net effect of this heat exchange during inspiration would be "cooling of the airways" [20], [21]. According to Mahler [34], water and heat are derived from the epithelium lining the inner wall of the airways. Inspirational air conditioning is a continuum that begins with the nose and terminates in tenth generation bronchi and bronchioles [34], [35].

\section{2) General Influences on the Exhaled Air}

Upon exhalation, some of the water in the exhaled air condenses and returns to the airway epithelial cells [35]. The result of the exchange of heat and water between the air and the epithelium during inhalation and expiration therefore results in a net loss of heat and water from the cells of the epithelium. Approximately $80 \%$ of the heat loss from the epithelium is caused by the evaporation of its water content [35].

\section{3) Effects of Exchanges between the Inspired Air and the} Exhaled Air on the Epithelium

In the lungs, the cholinergic parasympathetic system that plays a constrictor role is represented by cholinergic-mediated nerves. This system comprises afferent fibres that originate from the respiratory epithelium and bronchial smooth muscle. The efferent fibres are distributed at the level of smooth muscles and bronchial glands and play a bronchoconstrictor role. From disturbances to the epithelial cells due to heat loss, abnormalities are recorded at the parasympathetic level resulting in basic vagal hypertonia, which is responsible for an exaggerated muscle tone and excessive pressure of the receptors of the reflex arc that are very sensitive to various stimulations. These stimuli cause bronchoconstrictor effects by the disruption of cholinergic fibres that mediate. These effects result in hyperreactivity that can last for several weeks after exposure to stimuli. Eggleston suggested that the onset of exercise-induced bronchospasm is caused by increased airway sensitivity to fluid and caloric loss [36]. In fact, the loss of water in the mucosa of the respiratory tract causes a change in its osmolarity state. A loss of water then makes the medium in which the cells of the respiratory mucosa bathe hyperosmotic [35]. Indeed, the cells of the respiratory airways, such as mast cells, eosinophils, basophils and neutrophils, intervene by yielding water in the form of heat to condition the inspired air. As a result, an increase in $\left[\mathrm{Na}^{+}\right],\left[\mathrm{Cl}^{-}\right],\left[\mathrm{Ca}^{2+}\right]$ and $\left[\mathrm{K}^{+}\right]$ions causes the hyperosmolar state of the airways and induces bronchial spasm. Under these conditions of general influences and of the consequences suffered by both the inspired air and the exhaled air within respiratory airways, the quantity and quality of the ambient air are unavoidable variables to be considered as plausible explanations.

4) Effects induced if the Ambient Air Temperature is

below that of the Body $\left(<37^{\circ} \mathrm{C}\right)$

In this first condition, if the temperature of the inhaled ambient air is lower than that of the body, which is $37^{\circ} \mathrm{C}$, the saturation of the inspired air in water and its warming to body temperature would require a significant contribution of respiratory tracts. During exercise, the hyperventilation of cold air with a temperature lower than that of the body would dehydrate the mucous membranes of the airways and induce bronchial and/or thermal stress. Similarly, because of the high ventilation rate, the upper respiratory tract would no longer be able to properly humidify and warm the inspired air at body temperature and at $100 \%$ saturation [21]. Under these conditions, large quantities of inspired air without conditioning would be found in the lower airways, which must be solicited for conditioning. This mechanism significantly alters the temperature and triggers the hyperosmolarity of all airways. This effect naturally leads to an inflammatory state of the bronchi and small lower airways, eventually leading to bronchospasm [37], [38]. Moreover, according to Mahler [34], intra-pulmonary temperatures would decrease (cold) during the effort and gradually increase (hot) at the end of the exercise. From these events, we can assume the hypothesis that when the ambient air inhaled is at a temperature lower than that of the body, exercise-induced bronchospasm is exacerbated in both the upper and lower respiratory tracts. Unfortunately, the diagnosis of EIB based on variations in FEV post-exercise does not always take into account the disturbances of small ventilatory flows. The question arises as to whether the evaluation of EIB under these conditions was not underestimated.

5) Effects induced if the Ambient Air Temperature is higher than that of the $\operatorname{Body}\left(>37^{\circ} \mathrm{C}\right)$

During this second condition, if the ambient air inhaled is at a temperature higher than that of the organism, then the central problem is to determine the mechanism by which the organism can reduce the temperature to $37^{\circ} \mathrm{C}$. 
Mahler [34] showed that during the effort, the cells of the epithelium are in a state of freshness; thus, we can speculate that the low temperatures of the epithelial cells make it possible to lower the high temperature ambient air inhaled to that of the body. Given hyperventilation and the nature and intensity of the effort, this process can also induce bronchospasm in the upper airways. As previously stated, the quantities of inhaled air at high temperatures will produce heat because of the coolness of the small lower respiratory tracts.

\section{CONCLUSION}

The prevalence values of exercise-induced bronchospasm observed in athletes in cold and dry air climates are increasing. On the other hand, prevalence in hot and humid air climates is decreasing. The literature suggests that the high temperature of the air inhaled during exercise is an explanatory factor for the low prevalence values. However, conflicting results on EIB prevalence values are observed in tropical areas. Based on the assumptions made in this review, we suggest that sport-and exercise-induced bronchospasm is as important in hot, humid air as it is in cold, dry air. The variability in the EIB prevalence values on which the controversies are based is mainly due to the training state of the subjects, the nature and intensity of the effort, the diagnostic parameters and assessment criteria and the high level of hyperventilation of hot or cold air. We hypothesize that in cold and dry air environments, the small lower airways of athletes are more vulnerable than those of their counterparts to pathophysiology in hot and humid climates. Professional sportsmen specializing in long-distance endurance sports truly expose their small airways to various pathologies.

\section{REFERENCES}

[1] Gibson GJ, Loddenkemper R, Lundbäck B, Sibille Y. (2013) Respiratory health and disease in Europe: The new European Lung White Book. Eur Respir J. 42:559-63. https://doi.org/10.1183/09031936.00105513.

[2] Pallari E, Lewison G, Sullivan R. (2017) How is chronic non-communicable respiratory conditions research reported in European newspapers? An impact assessment for policy. Clin Respir J. 11:657-665. https://doi.org/10.1111/crj.12685.

[3] Cruz ÁA, Stelmach R, Ponte E V. (2017) Asthma prevalence and severity in low-resource communities. Curr Opin Allergy Clin Immunol. 17(3):188-93. https://doi.org/10.1097/ACI.0000000000000360.

[4] World Health Organization. (2007) Global surveillance, prevention and control of chronic respiratory diseases: a comprehensive approach. Chronic respiratory disease. 1-146. https://doi.org/10.1177/1479972306070070.

[5] Anandan C, Nurmatov U, Van Schayck OCP, Sheikh A. (2010) Is the prevalence of asthma declining? Systematic review of epidemiological studies. Allergy Eur J Allergy Clin Immunol. 65(2):152-67. https://doi.org/10.1111/j.1398-9995.2009.02244.x.

[6] Deckers IAG, McLean S, Linssen S, Mommers M, van Schayck CP Sheikh A. (2012) Investigating international time trends in the incidence and prevalence of atopic eczema 1990-2010: a systematic review of epidemiological studies. PLoS One.;7(7):e39803. https://doi.org/10.1371/journal.pone.0039803.

[7] Asher MI, Montefort S, Björkstén B et al. (2006) Worldwide time trends in the prevalence of symptoms of asthma, allergic rhino conjunctivitis, and eczema in childhood: ISAAC phases one and three repeat multi country cross-sectional surveys. Lancet. 368:733-43.

[8] Davies RD, Parent EC, Steinback CD, Kennedy MD. (2018) The Effect of Different Training Loads on the Lung Health of Competitive Youth Swimmers. Int J Exerc Sci. 11(6):999-1018.
[9] Rundell KW, Wilber RL, Szmedra L, Jenkinson DM, Mayers LB, Im J. (2000) Exercise-induced asthma screening of elite athletes: field versus laboratory exercise challenge. Med Sci Sports Exerc. 32(2):309-16. https://doi.org/10.1097/00005768-200002000-00010.

[10] Wilber RL, Rundell KW, Szmedra L, Jenkinson DM, IM J DS. (2000) Incidence of exercise-induced bronchospasm in Olympic winter sport athletes. Med Sci Sport Exerc. 32(4):732-7.

[11] Chen WY HD. (1977) Heat and water loss from the airways and exercise-induced asthma. Respiration. 34(6):305-13.

[12] Anderson SD. (2016) 'Indirect' challenges from science to clinical practice. Eur Clin Respir J. 3(1):31096. https://doi.org/10.3402/ecrj.v3.31096.

[13] McFadden ER, Ann Lenner KM, Strohl KP. (1986) Postexertional Airway Rewarming and Thermally Induced Asthma New Insights into Pathophysiology and Possible Pathogenesis. J Clin Invest. 78(1):18-25. https://doi.org/10.1172/JCI112549.

[14] Rodrigues Filho E, Aurélio de Valois Correia Junior M, Batista G, Henrique Souza de Almeida A, Luis Mousinho Gomes R, de Albuquerque Rodrigues Filho E et al. (2018) Exercise-Induced Bronchospasm in Soccer Athletes Living in a Tropical Humid Region. J Sports Med Doping Stud. 8(1):1000200. https://doi.org/10.4172/2161-0673.1000200.

[15] Messan F, Dansou PH, Lawani MM, Falola J, Gouthon P. (2011) Prévalence du bronchospasme induit par 1' exercice chez des basketteurs amateurs en climat chaud et humide. Rev CAMES-Série A,. 12(1):28-33.

[16] Nsompi F, Messan F, Tito A, Lawani MM. (2018) Prevalence of exercise-induced bronchospasm among athletes in the hot and humid climate of brazzaville, Congo. Int J Dev Res. 8(12):24473-9. http://www.journalijdr.com.

[17] Ouattara S, Balayssac-Siransy A E, Konaté A, Tuo N, Keita M, Dah C, \& Bogui P. (2012) Bronchospasme induit par l'exercice chez des sportifs de compétition en milieu tropical humide. Sci Sport. 27(1):1-8. https://doi.org/10.1016/j.scispo.2011.08.001.

[18] Agodokpessi G, Ade G, Ahounou FJ, Gbenou DJ, Dansou HP, Gninafon M. (2012) [Bronchoconstriction induced by exercise in the black African athlete]. Mali Med.;27(1):33-6. Available from: http://www.ncbi.nlm.nih.gov/pubmed/22766493.

[19] Freed AN. (1995) Models and mechanisms of exercise-induced asthma. Eur Respir J. 8:1770-85.

[20] McFadden J. (1990) Hypothesis: exercise-induced asthma as a vascular phenomenon. Elsevier.335(8694):880-3. https://www.sciencedirect.com/science/article/pii/014067369090478 N.

[21] Deal EC JR, McFadden ER Jr, Ingram RH Jr JJ. (1979) Oesophageal temperature during exercise in asthmatic and non asthmatic subjects. J Appl Physiol. 46(3):484-90. https://doi.org/10.1152/jappl.1979.46.3.484.

[22] Solway J. (1990) Airway heat and water fluxes and the trachea bronchial circulation. Eur Respir J. 12:608s-617s.

[23] Brunekreef B, Hoek G, Breugelmans O LM. (1994) Respiratory effects of low-level photochemical air pollution in amateur cyclists. Am J Respir Crit Care Med. 150(4):962-966. https://doi.org/10.1164/ajrccm.150.4.7921470.

[24] Kinney PL, Nilsen DM, Lippmann M, Brescia M, Gordon T, Mcgovern T et al. (1996) Biomarkers of lung inflammation in recreational joggers exposed to ozone. Am J Respir Crit Care Med.;154(5):1430-1435. https://doi.org/10.1164/ajrccm.154.5.8912760.

[25] Hinds WC. (1999) Aerosol Technology Properties, Behavior, and Measurement ofAirborne Particles Second Edition. J Aerosol Sci. 14(2):175. https://doi.org/10.1016/0021-8502(83)90049-6

[26] Brüske-Hohlfeld I, Rosario AS, Wölke G, Heinrich J, Kreuzer M, Kreienbrock L, Wichmann H-E. (2006) Lung cancer risk among former uranium miners of the WISMUT Company in Germany. Health Phys. 90(3):208-16. http://www.ncbi.nlm.nih.gov/pubmed/16505617

[27] Anderson SD, Connolly NM, Godfrey S. (1971) Comparison of bronchoconstriction induced by cycling and running. Thorax. 26(4):396-401. https://doi.org/10.1136/thx.26.4.396.

[28] Thole RT, Sallis RE, Rubin AL, Smith GN. (2001) Exercise-induced bronchospasm prevalence in collegiate cross-country runners. Med Sci Sports Exerc. 33(10):1641-6. https://doi.org/10.1097/00005768-200110000-00005.

[29] Rundell KW, Im J, Mayers LB, Wilber RL, Szmedra L, Schmitz HR (2001) Self-reported symptoms and exercise-induced asthma in the elite athlete. Med Sci Sports Exerc. 33(2):208-13. https://doi.org/10.1097/00005768-200102000-00006. 
[30] Bougault V, Turmel J, Boulet LP. (2010) Bronchial challenges and respiratory symptoms in elite swimmers and winter sport athletes: Airway hyperresponsiveness in asthma: Its measurement and clinical significance. Chest. 138(2SUPPL):31S-37S. https://doi.org/10.1378/chest.09-1689.

[31] Nystad W, Harris J, Borgen JS. (2000) Asthma and wheezing among Norwegian elite athletes. Med Sci Sports Exerc. 32(2):266-70. https://doi.org/10.1097/00005768-200002000-00003.

[32] Rundell KW, Spiering BA, Evans TM BJ. (2004) Baseline lung function, exercise-induced bronchoconstriction, and asthma-like symptoms in elite women ice kockey players. Med Sci Sport Exerc. 36(3):405-10 https://doi.org/10.1249/01.MSS.0000117118.77267.BF.

[33] Storms WW. (2003) Review of exercise-induced asthma. Med Sci Sports Exerc. 35(9):1464-70. https://doi.org/10.1249/01.MSS.0000084533.75912.B4.

[34] Mahler D. (1993) Exercise-induced asthma. Med Sci Sport Exerc. 25:554-61.

[35] Lemanske RF, Henke KG. (1989) Perpective in exercise, Science and Sport medecine, Youth, Exercice and Sport. Benchowork Press inc. 2:465-510.

[36] Eggleston P. (1986) Pathophysiology of exercise-induced asthma. Med SciSport Exerc.18:318-21.

[37] Lonsdorfer-Wolf E. (2010) Sport et insuffisance respiratoire chronique. Sci Sport. 25:158-164. https://doi.org/10.1016/j.scispo.2010.05.002.

[38] Anderson SD, Fitch K, Perry CP, Sue-Chu M, Crapo R, McKenzie D, Magnussen H. (2003) Responses to bronchial challenge submitted for approval to use inhaled beta2-agonists before an event at the 2002 Winter Olympics. J Allergy Clin Immunol.(1):45-50. https://doi.org/10.1067/mai.2003.1.

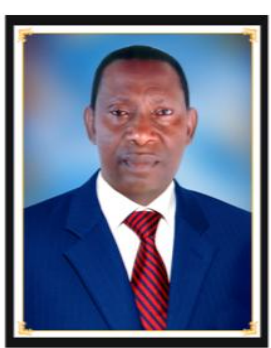

Address: 01 PB 169 INJEPS-

Porto-Novo (Benin)

ORCID ID:

https://orcid.org/0000-0002-8316-643 0

Brief Biographical History:

Mastery 1 and 2 at the Faculty of Sport and Sciences in the University of the Mediterranean (Aix-Marseille II, France) from 2001 to 2002

$\mathrm{PhD}$ at Doctoral School of Rennes 2

(France) from 2003 to 2007

Lecturer (CAMES) in 2015

Deputy Director of INJEPS (2016-2018)

Head of: Unit of Respiratory, Hormonal and Gerontological

Explorations of the Sportsman

Publications: 41 international publications

To see publications:

https://www.researchgate.net/profile/Folly_Messan

Main Works: Exercise-Induced Bronchospasm; Asthma and Sports; Pollution and Statistical Analysis

Folly MESSAN is Assistant Professor of Physiology since 2007 